\title{
Poly(fluorinated 3-alkoxy thiophene)
}

\author{
Ahmed El Kassmi, Werner Büchner, Fabienne Fache and Marc Lemaire * \\ Université Claude Bernard Lyon I, Laboratoire de Catalyse et Synthèse Organique, U.P. C.N.R.S. no. 5401, \\ Bât. 308, ESCIL, 43 boulevard du 11 novembre 1918, 69622 Villeurbanne CEDEX (France)
}

\section{INTRODUCTION}

It has been shown that the modification of the thiophene monomer by introduction in the 3 position of an alkyl group [1-3], an alkylsulphonic acid group [4] or a phenyl substituent [5] gives specific properties to the new polymers [6,7]. Recently, polyalkoxythiophenes have been reported as soluble electrical conducting polymers [8-10]; patents have also been published on the subject, which reveal the potential industrial interest of such compounds [11,12]. At the same time, studies on poly(fluorinated 3-alkylthiophenes) have been developed [13] because of the remarkable chemical and thermal stability of fluorinated polymers in general and with the purpose of having new monomers miscible with commercial fluoropolymers.

Here we want to report the synthesis of alkoxyfluorinated thiophene monomers, the optimization of the conditions of their chemical and/or electropolymerisation as well as their intrinsic properties as conductive polymers.

\section{EXPERIMENTAL}

Synthesis of the monomers

We have already described the introduction of a polyfluorinated alkoxy chain on a thiophene ring [14] by aromatic nucleophilic substitution catalysed by copper species. This original synthesis is summarized in Fig. 1. 
<smiles>Brc1ccsc1</smiles>

$+\mathrm{CF}_{3} \mathrm{CH}_{2} \mathrm{OH}$

$+\mathrm{CF}_{3}\left(\mathrm{CF}_{2}\right)_{n} \mathrm{CH}_{2} \mathrm{OH}$

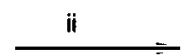<smiles>FC(F)(F)Oc1ccsc1</smiles>

1

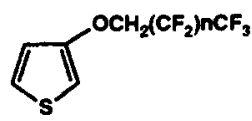

$\mathbf{2}: \mathbf{n}=\mathbf{2}$

$3: n=6$

Fig. 1. Reagents and conditions: (i) $\mathrm{NaH}, \mathrm{CuI}, \mathrm{DMF}, 110^{\circ} \mathrm{C}, 5 \mathrm{~h}$; (ii) $\mathrm{NaH}, \mathrm{CuI}, \mathrm{DME}, 90^{\circ} \mathrm{C}, 15 \mathrm{~h}$.

Synthesis of the polymers

Electrochemical synthesis

The electropolymerisation of these monomers was performed in a one-compartment cell; the concentration of the monomer, the nature and the concentration of the electrolyte, the solvent and the nature of the electrodes have been optimized and will be described later. All the solutions were degassed by argon bubbling prior to electropolymerisation. After polymerisation, the films were rinsed with acetone, dried and transferred to a cell containing the electrolyte in the appropriate solvent. All potentials refer to a saturated calomel electrode (SCE). The doping level $y$ was calculated from the amount of charge measured during the oxidation of the polymer $\left(Q_{\mathrm{o}}\right)$ and the amount of charge used for the film deposition $\left(Q_{\mathrm{d}}\right)$, using the relation $y=2 Q_{\mathrm{o}} /\left(Q_{\mathrm{d}}-Q_{\mathrm{o}}\right)$.

\section{Chemical synthesis}

Doped polymer. In a three-necked flask fitted with an efficient stirrer, a thermometer and a septum, $8.9 \mathrm{~g}(54.8 \mathrm{mmol})$ of anhydrous iron(III) chloride were dissolved in $80 \mathrm{ml}$ of chloroform, under nitrogen, the temperature being maintained at $+20^{\circ} \mathrm{C}$. Then, $20 \mathrm{ml}$ of chloroform and $2.5 \mathrm{~g}(13.7 \mathrm{mmol})$ of monomer 1 were added dropwise in $10 \mathrm{~min}$. The mixture was stirred during $2 \mathrm{~h}$. After filtration, the crude product was washed 5 times with $500 \mathrm{ml}$ of chloroform, dried in dynamic vacuum at $20^{\circ} \mathrm{C}$. $2.55 \mathrm{~g}$ of doped polymer 1 were obtained.

Dedoped polymer. The procedure is the same as the one described for the doped polymer, but after the $2 \mathrm{~h}$ stirring, the reaction mixture was poured into methanol. The resulting precipitate was filtered off, washed with methanol + water solution 
and filtered off again. The powder was treated with a $0.1 \mathrm{M}$ solution of $\mathrm{NH}_{4} \mathrm{OH}$ in a $1 / 1$ mixture of water + methanol. Finally, the powder was filtered off and dried in a dynamic vacuum at $20^{\circ} \mathrm{C} .2 .1 \mathrm{~g}$ of dedoped polymer were obtained.

\section{RESULTS AND DISCUSSION}

Poly(3-(2,2,2-trifluoroethoxy)-thiophene): poly 1

The optimized conditions for the galvanostatic polymerisation of monomer 1 (short chain) are summarized in Table 1 and the voltammogram of poly 1 is presented in Fig. 2. The highest doping level value we observed was $7 \%$ with a $I_{\mathrm{pa}} / I_{\mathrm{pc}}$ ratio of 1.6. As this polymer was soluble in the different solvents used for its electrosynthesis, the doping level values determined by cyclic voltammetry were representative of both the oxidation of the polymer and the synthesis yield. Nevertheless, this deposit polymer remained stable under cycling at $50 \mathrm{mV} \mathrm{s}^{-1}$ for several tens of cycles. The electrosynthesis yield of such a polymer was too low for large scale preparation, therefore we have realized the chemical synthesis of this polymer following the method described in the experimental part. The dedoped poly 1 thus obtained exhibits a solubility of $14 \times 10^{-3} \mathrm{~g}^{-1}$ in $\mathrm{CH}_{3} \mathrm{CN}$ and $26 \times 10^{-3} \mathrm{~g}^{-1}$ in THF. The conductivity of doped polymer in pressed pellets lies between $2 \times 10^{-1}$ and $10^{-2} \mathrm{~S} \mathrm{~cm}^{-1}$.

These properties (stability under cycling, solubility, conductivity) and the fact that poly 1 contains $31 \%$ of fluorine make this new polymer very interesting for further developments.

In the case of the poly(3-(2,2,3,3,4,4,4-heptafluorobutoxy)-thiophene), its solubility in electrosynthesis solvents was higher than the solubility of poly 1 and therefore its study will not be discussed here.

\section{TABLE 1}

Optimized conditions of polymerisation under galvanostatic conditions

\begin{tabular}{lll}
\hline Parameters & Poly 1 & Poly 3 \\
\hline Solvent & $\mathrm{CH}_{2} \mathrm{Cl}_{2}$ & $\mathrm{CH}_{3} \mathrm{CN}$ \\
Electrolyte & $\mathrm{NBu}_{4} \mathrm{PF}_{6}$ & $\mathrm{LiClO}_{4}$ \\
[Electrolyte] & 50 & 50 \\
$/ \mathrm{mmol}^{-1}$ & $\mathrm{Pt}$ & \\
Electrode & 100 & $\mathrm{Pt}$ or ITO \\
{$[$ Monomer] } & & 100 \\
$/ \mathrm{mmol} \mathrm{I}^{-1}$ & 4 & 1.9 \\
$j / \mathrm{mA} \mathrm{cm}^{-2}$ & 7 & 21.4 \\
$y / \%$ & & \\
\hline
\end{tabular}

Conditions: scan rate, $50 \mathrm{mV} \mathrm{s}^{-1}$; potential range, $+0.05-+1.25 \mathrm{~V} / \mathrm{SCE}$. 


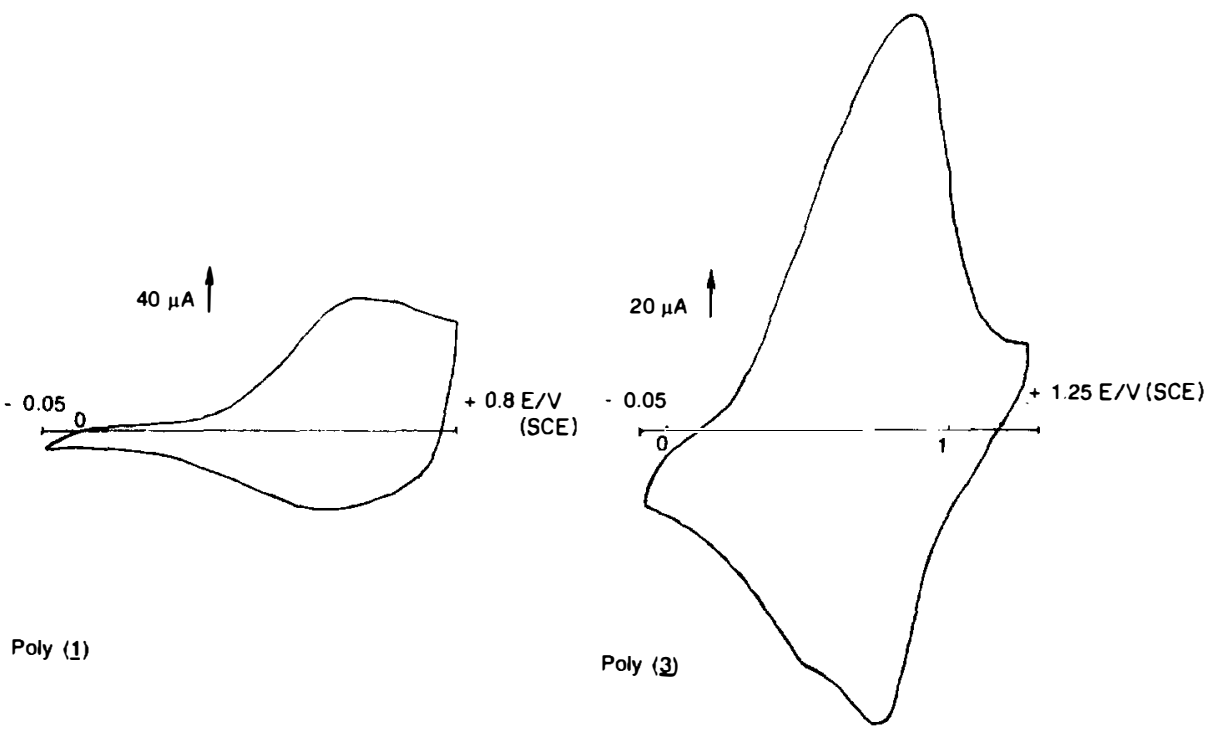

Fig. 2. Cyclic voltammograms of films of poly 1 and poly 3, prepared on $\mathrm{Pt}$ using $200 \mathrm{mC} \mathrm{cm}{ }^{-2}$ (in $\mathrm{NBu}_{4} \mathrm{PF}_{6}+\mathrm{CH}_{2} \mathrm{Cl}_{2}$ for poly 1 and in $\mathrm{LiClO}_{4}+\mathrm{CH}_{3} \mathrm{CN}$ for poly 3); scan rate, $50 \mathrm{mV} \mathrm{s}^{-1}$.

Poly(3-(2,2,3,3,4,4,5,5,6,6,7,7,8,8,8-pentadecafluorooctyloxy)-thiophene): poly 3

The optimized conditions for the galvanostatic or the potentiostatic polymerisation of monomer 3 (long chain) are described in Tables 1 and 2 respectively. The voltammogram of poly 3 is presented in Fig. 2 . With our optimized conditions, only one system could be observed for poly 3 , but with other electrolytes like $\mathrm{LiPF}_{6}$ or $\mathrm{NBu}_{4} \mathrm{SO}_{3} \mathrm{CF}_{3}$, two redox systems were obtained. This is a classical result for polymers bearing an ether group in their 3 substituent. The origin of the phenomenon is still a matter of investigation [15]. It is noteworthy that under potentiostatic conditions we obtained a higher doping level value than under galvanostatic conditions ( $26 \%$ instead of $21.4 \%$ ). Nevertheless, under potentiostatic conditions the optimal potential range was very narrow: at $1.6 \mathrm{~V} / \mathrm{SCE}$, no polymerisation was observed and at $1.9 \mathrm{~V} / \mathrm{SCE}$ the doping level value fell down to $9 \%$. As quite a good doping level value had been obtained with poly 3 in optimized

TABLE 2

Optimized conditions for the potentiostatic polymerisation of monomer 3

\begin{tabular}{llllll}
\hline Solvent & Electrolyte & $\begin{array}{l}\text { [Electrolyte] } \\
/ \mathrm{mmol} \mathrm{I}^{-1}\end{array}$ & Electrode & $\begin{array}{l}\mathrm{E} / \mathrm{V} \\
\text { (SCE) }\end{array}$ & $\begin{array}{l}y / \\
\%\end{array}$ \\
\hline $\mathrm{CH}_{3} \mathrm{CN}$ & $\mathrm{LiClO}_{4}$ & 20 & $\mathrm{Pt}$ & 1.8 & 26 \\
\hline
\end{tabular}

Conditions: potential range, $+0.05-+1.25 \mathrm{~V} / \mathrm{SCE}$; scan rate, $50 \mathrm{mV} \mathrm{s}^{-1}$. 


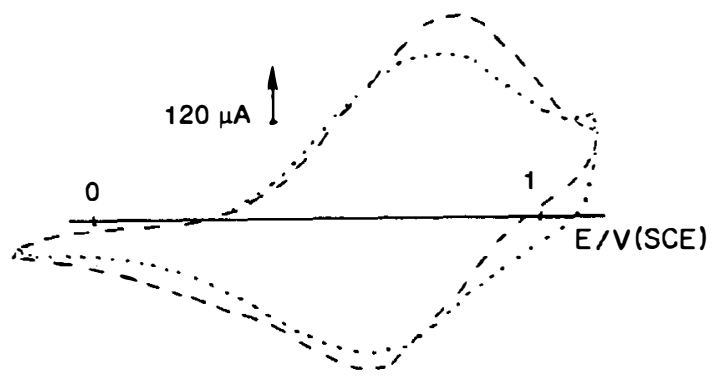

Poly (3)

Fig. 3. Stability under cycling of film of poly 3 in $\mathrm{CH}_{3} \mathrm{CH}+\mathrm{LiClO}_{4} 0.1 \mathrm{~mol} \mathrm{l}^{-1}$; scan rate, $200 \mathrm{mV} \mathrm{s}^{-1}$; potential range, $0-1.15 \mathrm{~V} / \mathrm{SCE}$.

galvanostatic conditions, we studied the stability of this polymer synthesized under these conditions (Fig. 3): after 3000 cycles between 0 and $+1.15 \mathrm{~V} / \mathrm{SCE}$ at 200 $\mathrm{mV} \mathrm{s}^{-1}, 70 \%$ of the electroactivity was recovered. To compare poly 3 to the well known stable polymers poly(3-methylthiophene) [16] and poly(3-octylthiophene) [17], we studied its stability under cycling at $50 \mathrm{mV} \mathrm{s}^{-1}$ between -0.05 and +1.2 $\mathrm{V} / \mathrm{SCE}$. The results are summarized in Fig. 4. Poly 3 lost its electroactivity rapidly compared with the two other polymers, but after rapid stabilisation around $y=10 \%$ (after 300 cycles) it remained stable for several hundreds of cycles and then exchanged the same charge as the two other polymers.

Films of $4 \mu \mathrm{m}$ thickness have been obtained by polymerisation of monomer 3 on an ITO glass electrode covered by a thin film of $10 \mathrm{mC}$ of poly(3-methylthiophene).

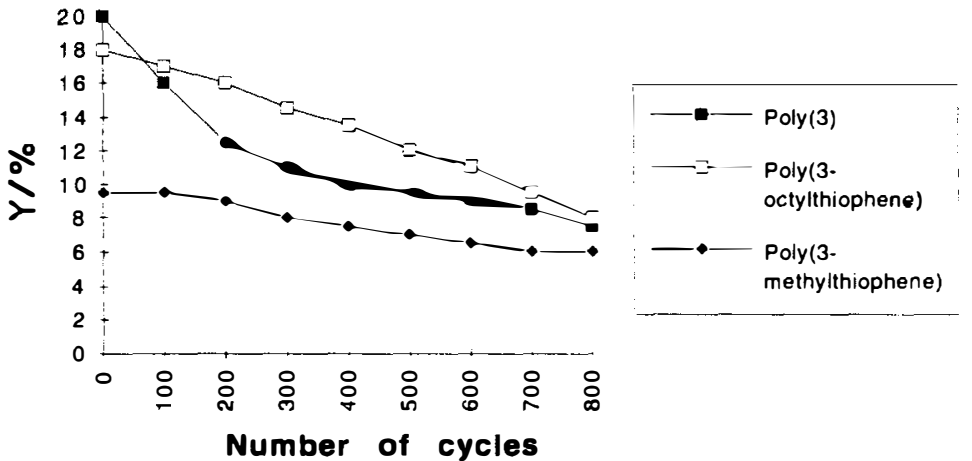

Fig. 4. Comparative study of the stability of different polymers $\left(\mathrm{LiClO}_{4}+\mathrm{CH}_{3} \mathrm{CH}: 100 \mathrm{mmol} \mathrm{1}{ }^{-1}\right.$; scan rate, $50 \mathrm{mV} \mathrm{s}^{-1}$; potential range, -0.05 to $+1.2 \mathrm{~V} / \mathrm{SCE}$ ). 
A conductivity of 1 to $10 \mathrm{~S} \mathrm{~cm}^{-1}$ evaluated by the four-probe measurement method was observed.

\section{CONCLUSIONS}

In summary, we have shown that it is possible to polymerize monomers with a polyfluoralkoxy chain as a 3-substituent, leading, in the case of the short chain (poly 1), to an interesting soluble material and, in the case of the long chain (poly 3), to a polymer which exhibits a high doping level and stability compared with its polyalkylated analogue.

\section{REFERENCES}

1 K.Y. Jen, G.G. Miller and R.L. Elsenbaumer, J. Chem. Soc., Chem. Commun., (1986) 1346.

2 M.A. Sato, S. Tanaka and K. Kaeriyama, J. Chem. Soc., Chem. Commun., (1986) 873.

3 M. Lemaire, R. Garreau, F. Garnier and J. Roncali, New J. Chem., 11 (1987) 703.

4 A.O. Patil, Y. Ikenoue, F. Wudl and A.J. Heeger, J. Am. Chem. Soc., 107 (1987) 1858.

5 M.A. Sato, S. Tanaka and K. Kaeriyama, J. Chem. Soc., Chem. Commun., (1987) 1725.

6 J. Roncali, R. Garreau, D. Delabouglise, F. Garnier and M. Lemaire, J. Chem. Soc., Chem. Commun., (1989) 679.

7 M. Lemaire, D. Delabouglise, R. Garreau, A. Guy and J. Roncali, J. Chem. Soc., Chem. Commun., (1988) 658.

8 M. Feldhues, G. Kämpf, H. Litterer, T. Mecklenburg and P. Wegener, Synth. Met., 28 (1989) C487.

9 R.L. Blankespoor and L.L. Miller, J. Chem. Soc., Chem. Commun., (1985) 90.

10 A. Chissel, P. Kathirganamathan, D. Parker and N.R.M. Smith, J. Chem. Soc., Chem. Commun., (1987) 446.

11 D. Parker, P. Kathirgamanathan, N.R.M. Smith, M.R. Bryce and A.D. Chissel, Eur Pat. 0253594A2, 1988.

12 M. Feldhues, T. Mecklenburg, P. Wegener and G. Kämpf, Eur. Pat. 0257573A1, 1988.

13 B. Willoughby, in R. Banks (Ed.), Preparation, Properties and Industrial Applications of Organofluorine Compounds, Ellis Horwood Series in Chemical Sciences, Chichester, 1982.

14 A. El Kassmi, G. Héraud, W. Büchner, F. Fache and M. Lemaire, J. Mol. Catal., 72 (3) (1992) 299.

15 J. Roncali, Li Hong Shi, R. Garreau, F. Garnier and M. Lemaire, Synth. Met., 36 (1990) 267.

16 G. Tourillon and F. Garnier, J. Electroanal. Chem., 135 (1982) 173.

17 J. Roncali, R. Garreau, A. Yassar, P. Marque, F. Garnier and M. Lemaire, J. Phys. Chem., 91 (1987) 6706. 